\title{
Chryseobacterium gleum in a man with prostatectomy in Senegal: a case report and review of the literature
}

\author{
O. Arouna ${ }^{1 *}$, F. Deluca², M. Camara' ${ }^{1}$ B. Fall ${ }^{3}$, B. Fall ${ }^{4}$, A. Ba Diallo', J. D. Docquier ${ }^{2}$ and S. Mboup ${ }^{1}$
}

\begin{abstract}
Background: Here we report a rare case of a urinary tract infection due to Chryseobacterium gleum. This widely distributed Gram-negative bacillus is an uncommon human pathogen and is typically associated with health care settings.

Case presentation: We describe a case of urinary tract infection caused by Chryseobacterium gleum in a 68-year-old man of Wolof ethnicity (an ethnic group in Senegal, West Africa) who presented to our Department of Urology in a university teaching hospital (Hôpital Aristide Le Dantec) in Dakar, Senegal, 1 month after prostatectomy. The strain isolated from a urine sample was identified as Chryseobacterium gleum by mass spectrometry (Vitek matrix-assisted laser desorption/ionization, time-of-flight, bioMérieux) and confirmed by 165 ribosomal ribonucleic acid sequencing. The organism was resistant to a wide range of antibiotics, including carbapenem, due to a resident metallo- $\beta$ lactamase gene that shared $99 \%$ of amino-acid identity with Chryseobacterium gleum class B enzym.

Conclusions: Infection by Chryseobacterium gleum is infrequent, and no such case has been previously reported in Africa. Despite its low virulence, Chryseobacterium gleum should be considered a potential opportunistic and emerging pathogen. Further studies on the epidemiology, pathogenicity, and resistance mechanisms of Chryseobacterium gleum are needed for better diagnosis and management.
\end{abstract}

Keywords: Chryseobacterium gleum case report, Urinary tract infection, Metallo- $\beta$-lactamase, CGB-1, resistance

\section{Background}

The genus Chryseobacterium (formerly Flavobacterium) [1], whose type species is Chryseobacterium gleum [2] and belongs to the family Flavobacteriaceae (phylum Bacteroidetes), represents a group of Gram-negative, non-fermenting, catalase-positive, and indole-positive aerobic bacilli. Chryseobacterium species are uncommon human pathogens, and most cases are nosocomial and are often associated with immunosuppression or indwelling devices. Chryseobacterium is typically found in soil, water, plants, and food products and can survive in hospital environments, chlorinated water, and wet surfaces, all of which serve as potential reservoirs of infection. A literature search revealed only a few published cases in countries including Hungary, India, Croatia, and

\footnotetext{
* Correspondence: Oarouna2@gmail.com

'Laboratoire de Bactériologie-Virologie, CHNU Aristide Le Dantec, Université

Cheikh Anta Diop, BP 7325 Dakar, Senegal

Full list of author information is available at the end of the article
}

Saudi Arabia [3-6]. In Senegal, two cases of meningitis due to Flavobacterium meningosepticum were diagnosed in the late 1970s [7] as well as one case of Chryseobacterium indologenes [8]. However, human C. gleum infection has not been previously reported in Africa.

Here, we report the first case of C. gleum infection occurring in Africa and provide a review of similar cases worldwide (Table 1).

\section{Case presentation}

A 68-year-old man of Wolof ethnicity (an ethnic group in Senegal, West Africa) presented to our Department of Urology with severe dehydration and general deterioration of condition 1 month after prostatectomy via transurethral resection performed at a regional hospital. At hospital admittance, a clinical examination found a high blood pressure $(180 / 90 \mathrm{mmHg})$ and a fever of $38.5{ }^{\circ} \mathrm{C}$. Blood tests found leukocytosis with a level of $17,100 / \mathrm{mL}$ white blood cells (WBC), anemia with a level 
Table 1 Case reports of infection by Chryseobacterium gleum

\begin{tabular}{lllllll}
\hline Author & Country & ${\text { Sex }{ }^{\mathrm{a}} \text { Age }}$ & Site & Outcome & Factors & Antibiotic treatment \\
\hline Virok et al. (2014) [3] & Hungary & Newborns & Stomach content & Cured & Respiratory tract involvement & Ciprofloxacin \\
Garg et al. (2015) [18] & India & M/48 & Urine & Cured & Pyonephrosis & Tetracycline \\
Dijana et al. (2015) [5] & Croatia & F/35 & Blood/Tracheal aspirate & Cured & Hepatic lesion/malnutrition & Piperacillin/Tazobactam \\
Ramya et al. (2015) [4] & India & M/62 & Urine & Cured & Renal calculi/Hydronephrosis & Piperacillin/Tazobactam \\
Baha et al. (2016) [6] & Saudi Arabia & Newborn & Endotracheal aspirate & Cured & Nephrotic syndrome & Levofloxacin \\
Our case (2016) & Senegal & M/68 & Urine & Cured & Prostatectomy & Ciprofloxacin \\
\hline
\end{tabular}

${ }^{\mathrm{a}} M$ male, $F$ female

${ }^{\mathrm{b}} Y$ year

of $10 \mathrm{~g} / \mathrm{dL}$, and creatinine with a level of $513.3 \mu \mathrm{mol} / \mathrm{L}$. Serum electrolytes showed hyponatremia with a level of $111 \mathrm{mEq} / \mathrm{L}$, hypokalemia with a level of $3.3 \mathrm{mEq} / \mathrm{L}$, and hypochloremia with a level of $77 \mathrm{mEq} / \mathrm{L}$. At presentation, he had an indwelling urinary catheter draining urine incorrectly that required a urine bacteriology examination.

Treatment consisted of fluid and electrolyte replacement, daily dressing of the wound, and empiric antibiotic therapy with amikacin. This drug was chosen because of the severity of the infection and because our patient had previously received treatment with fluoroquinolone. Seven days after hospitalization, the outcome was favorable with a clean surgical wound and normalization of serum potassium and chloride levels. However, hyponatremia persisted at $119 \mathrm{mEq} / \mathrm{L}$, and his serum creatinine level was $150.45 \mu \mathrm{mol} / \mathrm{L}$. Removal of the urinary catheter was performed on day 7 of hospitalization, and he returned home the same day.

The cloudy urine collected for bacteriology examination at hospitalization was inoculated on a cysteine lactose electrolyte deficient (CLED) agar plate according to the usual techniques for medical bacteriology. Direct examination showed a rich bacterial flora, many white cells, and Gram-negative bacilli by Gram staining. The CLED agar grew yellow-colored 1 to $2 \mathrm{~mm}$ circular colonies $\left(>10^{6} \mathrm{CFU} / \mathrm{mL}\right)$ with regular margins.

After culture, Chryseobacterium species was suspected because of the yellow-colored colonies due to flexirubin production. Identification using the Appareil et Procédés d'Identification $20 \mathrm{NE}$ identification system (bioMérieux, France) gave Myroides species and C. indologenes after, respectively, 24 hours and 48 hours of incubation (Table 2).

However, mass spectrometry (Vitek MS matrix-assisted laser desorption/ionization, time-of-flight, bioMérieux) successfully identified C. gleum and the result was confirmed using $16 \mathrm{~S}$ ribosomal ribonucleic acid (rRNA) sequencing.

In this case, $C$. gleum was confirmed as the causative agent for our patient's urinary tract infection as evidenced from the culture reports. Confluent growth of the organism in pure form from urine helped to rule out contamination.
Antimicrobial susceptibility testing using disc diffusion and E-tests (bioMérieux) for the minimum inhibitory concentration (MIC) using Pseudomonas aeruginosa ATCC 27853 and Escherichia coli ATCC 25922 for internal quality control was completed and interpreted per the Comité d'Antibiogramme de la Société Française de Microbiologie (CA-SFM) recommendations of 2015. The isolated strain was susceptible to piperacillin (MIC $=6 \mu \mathrm{g} / \mathrm{mL}$ ), ceftazidime $(\mathrm{MIC}=0.75 \mu \mathrm{g} / \mathrm{mL})$, cefepime $(\mathrm{MIC}=0.125 \mu \mathrm{g} / \mathrm{mL})$, ciprofloxacin $(\mathrm{MIC}=0.25 \mu \mathrm{g} / \mathrm{mL})$, imipenem $(\mathrm{MIC}=2 \mu \mathrm{g} /$ $\mathrm{mL}$ ), and resistant to meropenem ( $\mathrm{MIC}=8 \mu \mathrm{g} / \mathrm{mL}$ ), aztreonam $(\mathrm{MIC} \geq 256 \mu \mathrm{g} / \mathrm{mL}$ ), ticarcillin (MIC $\geq 256 \mu \mathrm{g} / \mathrm{mL}$ ), ticarcillin-clavulanic acid (MIC $=64 \mu \mathrm{g} / \mathrm{mL})$, and cefotaxime (MIC $>32 \mu \mathrm{g} / \mathrm{mL}$; Table 3).

Due to the decreased susceptibility to carbapenem, a combined test with imipenem and ethylenediaminetetraacetic acid (EDTA) was positive, indicating the production of metallo- $\beta$-lactamase (MBL). To characterize the gene encoding MBL, polymerase chain reaction (PCR) was performed using genomic deoxyribonucleic acid (DNA) obtained by phenol-chloroform extraction, using the template primers CGB1_exp/fw (5'-GGGAATTCCATATGAAAAAAAGCATTCCGTTTTTTA) and CGB1_exp/rv (CGCGGATCCTTATTTTTTATTTAAAAGATCAAG) as described previously by Bellais and colleagues [9]. DNA sequence analysis of the 726-base pairs (bp) amplified

Table 2 Identification of the strain using Appareil et Procédés d'Identification 20 NE (V7.0)

\begin{tabular}{|c|c|c|c|c|}
\hline & \multicolumn{2}{|l|}{$\% \mathrm{ID}$} & \multicolumn{2}{|l|}{$T$} \\
\hline & $24 \mathrm{H}$ & $48 \mathrm{H}$ & $24 \mathrm{H}$ & $48 \mathrm{H}$ \\
\hline \multicolumn{5}{|l|}{ Significant taxa } \\
\hline Myroides species & 61.2 & - & 0.67 & - \\
\hline Chryseobacterium indologenes & 34.2 & 99.9 & 0.84 & 0.42 \\
\hline \multicolumn{5}{|l|}{ Next taxon } \\
\hline Bergeyella zoohelcum & 4.4 & - & 0.5 & - \\
\hline Shewanella putrefaciens group & & 0.1 & & 0.0 \\
\hline
\end{tabular}

$24 \mathrm{H} 24$ hours of incubation, $48 \mathrm{H} 48$ hours of incubation, \%ID identification percentage (proximity relative to the different taxa in the database. It is determined whether the observed profile is closer to a particular taxon), $T$ typicality (the most typical profile is the one that has no tests against the identification compared with percentages in the database for that taxon) 
Table $\mathbf{3}$ In vitro antimicrobial susceptibilities of the strain, and interpretation according to Comité d'Antibiogramme de la Société Française de Microbiologie 2015 recommendations, using Pseudomonas aeruginosa ATCC 27853 and Escherichia coli ATCC 25922 as quality control

\begin{tabular}{|c|c|c|c|c|c|}
\hline Antibiotics & $\begin{array}{l}\text { MIC } \\
(\mu \mathrm{g} / \mathrm{mL})\end{array}$ & $\begin{array}{l}\text { IZD } \\
(\mathrm{mm})\end{array}$ & $\begin{array}{l}\text { Breakpoint }^{a} \\
(\mu \mathrm{g} / \mathrm{mL})\end{array}$ & $\begin{array}{l}\mathrm{S} \\
(\mathrm{mm})\end{array}$ & $\overline{\text { Categorization }}$ \\
\hline Ticarcillin & $\geq 256$ & 0 & $\leq 16$ & $\geq 18$ & Resistant \\
\hline Ticarcillin + AC & 64 & 8 & $\leq 16$ & $\geq 18$ & Resistant \\
\hline Piperacillin & 6 & 26 & $\leq 16$ & $\geq 18$ & Susceptible \\
\hline Ceftazidime & 0.75 & 22 & $\leq 8$ & $\geq 16$ & Susceptible \\
\hline Cefotaxime & $>32$ & 8 & - & - & Resistant \\
\hline Cefepime & 0.125 & 37 & $\leq 8$ & $\geq 19$ & Susceptible \\
\hline Aztreonam & $\geq 256$ & 0 & $\leq 1$ & $\geq 50$ & Resistant \\
\hline Imipenem & 2 & 25 & $\leq 4$ & $\geq 20$ & Susceptible \\
\hline Meropenem & 8 & 15 & $\leq 2$ & $\geq 18$ & Resistant \\
\hline Ciprofloxacin & 0.25 & 30 & $\leq 0.5$ & $\geq 25$ & Susceptible \\
\hline Co-trimoxazole & 0.094 & 28 & - & - & Susceptible \\
\hline
\end{tabular}

- cefotaxime breakpoint not given, AC clavulanic acid, IZD inhibition zone diameter, MIC minimum inhibitory concentration, $S$ Susceptibility

${ }^{a}$ Antimicrobial susceptibilities interpretation was done according to Comité d'Antibiogramme de la Société Française de Microbiologie 2015 recommendations using Pseudomonas species as reference

fragments encoding a 242-amino acid preprotein showed 99\% similarity with CGB-1 (Fig. 1).

\section{Discussion}

C. gleum is an unusual human pathogen that has been reported as the cause of early neonatal respiratory infection in three neonates [3]. The most common species causing human disease is $F$. meningosepticum followed by $C$. indologenes and C. gleum [10]. Typically thought of as an organism of low virulence, $C$. gleum may cause serious infections, particularly among immunocompromised patients. Colonization of this organism in patients can occur via contaminated medical devices involving fluids, such as intubation tubes, respirators, humidifiers, and incubators for newborns, as previously reported [11]. Almost, all publications available in the literature refer to long hospital stays with prolonged antibiotic treatment ( $>14$ days), oncological disease, and most of the patients had immunosuppression or indwelling devices [8-11]. A recent case published in 2016 from Saudi Arabia, reported C. gleum pneumonia in a 6-month-old baby with nephrotic syndrome [6]. The patient, intubated, was previously on multiple courses of antibiotics including meropenem, ceftriaxone, and vancomycin. Virok et al. reported in 2014 a case of early neonatal respiratory infection due to C. gleum in Hungary [3]. In Croatia, Dijana et al. published in 2015 a case of C. gleum infection in a patient with malnutrition and hepatic lesion [5]. The patient with respiratory insufficiency had developed septic shock, which necessitated intubation and mechanical ventilation. Our patient underwent a prostatectomy in a regional hospital with indwelling catheter; he had a urinary tract infection due to C. gleum, similar to an Indian case reported by Ramya et al. in 2015 [4].

Little is known about the virulence factor(s) of the members of Chryseobacterium, although reports have indicated that biofilm and protease production are important mechanisms involved in the virulence of Elizabethkingia meningoseptica (formerly Chryseobacterium meningosepticum) and $C$. indologenes [11]. Biofilm production by $C$. indologenes in central venous catheter-related bloodstream infection was recently noted [12]. E. meningoseptica isolates

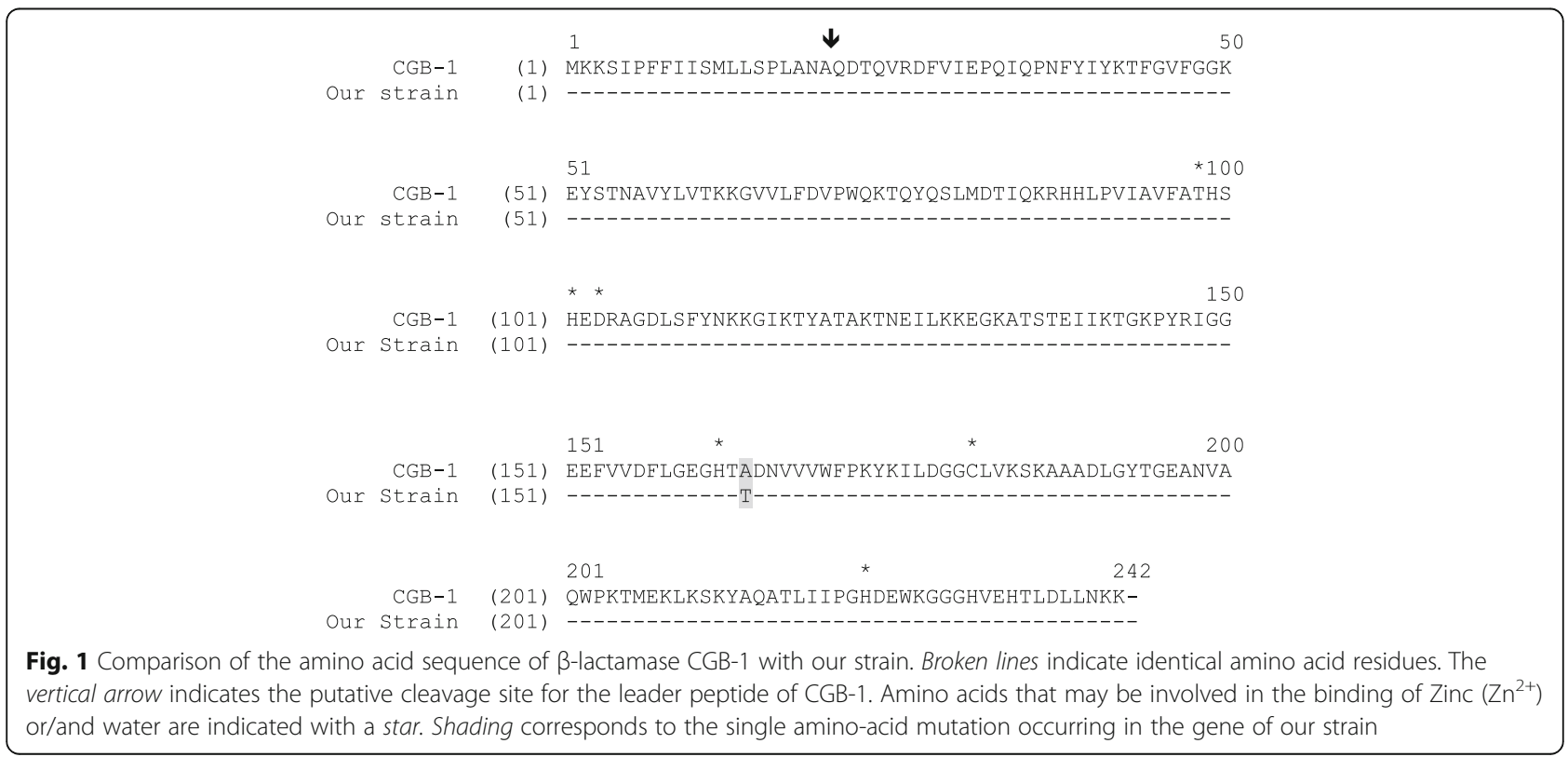


demonstrated $100 \%$ biofilm-forming ability in Luria-Bertani (LB) media, and increasing biofilm production is associated with the mortality rates of infected patients [13]. Lo and Chang performed a focused study on 14 C. gleum isolates [14], and the strains were epidemiologically unrelated and originated primarily from urine and sputum. Their study demonstrated that $40 \%$ of C. gleum isolates could form a biofilm. The biofilm-forming potential of C. gleum appeared to be much lower than that of $E$. meningoseptica. Therefore, it was suggested that C. gleum might be less virulent than E. meningoseptica and $C$. indologenes. In fact, we previously reported a fatal case of urinary tract infection due to $C$. indologenes in a woman with acute leukemia [8]. This outcome is in contrast to the present case, where the patient survived despite an advanced state of malnutrition.

Only $0.27 \%$ (50 of 18,569 ) of all processed nonfermenting Gram-negative bacilli (NFGNBs) and 0.03\% (50 of 15,5811) of isolates collected by the SENTRY Antimicrobial Surveillance Program during the 5-year period from 1997 to 2001 were members of the genera Chryseobacterium or Elizabethkingia (formerly Chryseobacterium), with the most frequent organisms being $E$. meningoseptica, $C$. indologenes, and C. gleum [15]. All 50 isolates were obtained from hospitalized patients, among which only two isolates (4\%) were identified as C. gleum. The present case is the first reported case of a urinary tract infection in Africa by C. gleum, although C. indologenes was previously reported in Burkina Faso in 2007 [16], in Senegal in 2014 [8], and in Tunisia in 2015 [17]. However, in Senegal, two cases of meningitis due to $F$. meningosepticum were diagnosed in the late 1970s [7].

There are few data available on antimicrobial susceptibility and no standardized breakpoints for Chryseobacterium species in CA-SFM guidelines due to the small number of clinical isolates. Thus, selecting an antimicrobial agent for the treatment of Chryseobacterium species infections remains difficult, especially because of chromosomal resistance to many antibiotics used for Gram-negative bacteria. According to the SENTRY Antimicrobial Surveillance Program, the antimicrobials most active against Chryseobacterium species are quinolones and sulfamethoxazole-trimethoprim ( $295 \%$ susceptibility) followed by piperacillin-tazobactam ( $90 \%$ susceptibility). Ciprofloxacin, cefepime, ceftazidime, piperacillin, and rifampicin showed reasonable activity (85\% susceptibility), whereas aminoglycosides, other $\beta$-lactams, chloramphenicol, linezolid, and glycopeptides are not appropriate for treating infections caused by this organism [15]. This conclusion is in concordance with the drug susceptibility pattern of the strain isolated in Senegal. In fact, most $C$. gleum infections have been preferentially treated by newer generations of quinolones than by the combination of piperacillin-tazobactam (Table 1). However, the strain isolated in Saudi Arabia was resistant to piperacillin-
Table 4 Minimum inhibitory concentrations of $\beta$-lactams for Chryseobacterium gleum CIP 103039, in comparison with our strain

\section{MIC $(\mu \mathrm{g} / \mathrm{mL})$ for:}

\begin{tabular}{lll}
\hline Antibiotics & Our strain & $\begin{array}{l}\text { Chryseobacterium gleum } \\
\text { CIP 103039 }\end{array}$ \\
\hline Ticarcillin & $\geq 256$ & 256 \\
Ticarcillin + AC & 64 & 256 \\
Piperacillin & 6 & 2 \\
Ceftazidime & 0.75 & 4 \\
Cefotaxime & $>32$ & 32 \\
Cefepime & 0.125 & 1 \\
Aztreonam & $\geq 256$ & $>512$ \\
Imipenem & 2 & 2 \\
Meropenem & 8 & 8
\end{tabular}

$A C$ clavulanic acid, MIC minimum inhibitory concentration

tazobactam. In addition, it was previously published that C. gleum CIP 103039 carried at least two likely chromosome-encoded $\beta$-lactamases, Amber class A CGA1 and Amber class B CGB-1, and was resistant to penicillins, cephalosporins, cefotaxime, and aztreonam, intermediate to carbapenems, and susceptible to piperacillin. Our strain showed the same drug susceptibility pattern as C. gleum CIP 103039 (Table 4). In contrast, the focused study of 14 C. gleum isolates conducted in Taiwan by Lo and Chang revealed that all isolates were resistant to piperacillin and imipenem [14].

\section{Conclusions}

To the best of our knowledge, this is the first case of a $C$. gleum infection reported in Africa. Despite their low virulence, Chryseobacterium species should be considered a potential opportunistic pathogen that can cause infection in hospitalized patients. This report highlights the emergence of Chryseobacterium infections in Africa and emphasizes the importance of strengthening hospital hygiene measures as well as the necessity to survey environmental bacteria that could cause hospital-acquired infections.

\section{Acknowledgements \\ We thank the practitioners of our Department of Urology for clinical data and the staff of the Laboratory of Bacteriology of the Aristide Le Dantec University Hospital for their technical assistance. We also thank the researchers at the Department of Medical Biotechnology, University of Siena (Italy), where work continues on this topic.}

Funding

Not applicable.

\section{Availability of data and materials}

Data sharing was not applicable to this article because no datasets were generated or analyzed during the current study. 


\section{Authors' contributions}

$\mathrm{OA}, \mathrm{FD}, \mathrm{MC}, \mathrm{BF}, \mathrm{BF}, \mathrm{ABD}, \mathrm{JDD}$, and $\mathrm{SM}$ conducted the case review and contributed to the writing of the case report. All authors read and approved the final report.

\section{Competing interests}

The authors declare that they have no competing interests.

\section{Consent for publication}

Written informed consent was obtained from the patient for publication of this case report and any accompanying images. A copy of the written consent is available for review by the Editor-in-Chief of this journal.

\section{Ethics approval and consent to participate}

The approval of the national ethics committee was solicited and has been obtained.

\section{Publisher's Note}

Springer Nature remains neutral with regard to jurisdictional claims in published maps and institutional affiliations.

\section{Author details}

'Laboratoire de Bactériologie-Virologie, CHNU Aristide Le Dantec, Université Cheikh Anta Diop, BP 7325 Dakar, Senegal. ²Dipartimento di Biotcnologie Mediche, Università degli Studi di Siena, Policlinico "Le Scotte", V lotto, II piano, Viale Bracci, 16, 53100 Siena (SI), Italy. ${ }^{3}$ Service d'Urologie, CHNU Aristide Le Dantec, BP 7325 Dakar, Senegal. ${ }^{4}$ Fédérations des laboratoires, Hôpital Principal de Dakar, 1, Avenue Nelson Mandela, Dakar, Senegal.

Received: 15 December 2016 Accepted: 15 March 2017

\section{Published online: 24 April 2017}

\section{References}

1. Vandamme P, Bernardet J, Segers P, Kersters K, Holmes B. New perspectives in the classification of the flavobacteria: Description of Chryseobacterium gen. nov. Bergeyella gen. nov., and Empedobacter nom. rev. Int J Syst Bacteriol. 1994:44:827-31.

2. Holmes B, Owen RJ, Steigerwalt AG, Brenner DJ. Flavobacterium gleum, a new species found in human clinical specimens. Int J Syst Bacteriol. 1984:34:21-5.

3. Virok DP, Abrok M, Szel B, Tajti Z, Mader K, Urban E, Talosi G. Chryseobacterium gleum - a novel bacterium species detected in neonatal respiratory tract infections. J Matern Fetal Neonatal Med. 2014;27(18):1926-9.

4. Ramya TG, Sabitha B, Pravin D, Geetha R. Chryseobacterium gleum urinary tract infection. Genes Rev. 2015:1(1):1-5.

5. Dijana VB, Ozrenka Z, Branka B, Vanda P. Chryseobacterium gleum infection in patient with extreme malnutrition and hepatic lesion - case report. Signa Vitae. 2015;10 suppl 1:50-2

6. Baha A, Nasreldin E, Khaldoon A, Reem A. Chryseobacterium gleum pneumonia in an infant with nephrotic syndrome. IDCases. 2016;5:34-6.

7. Samb A, Chiron JP, Denis F, Sow A, Diop MI. Flavobacterium meningosepticum meningitis. Clinical and bacteriological study of 2 cases treated in Senegal. Bull Soc Med A. 1977;22(1):84-91.

8. Arouna O, Camara M, Fall S, Ngom-Cisse S, Fall B, Ba-Diallo A, Diop-Ndiaye $\mathrm{H}$, Toure-Kane C, Mboup S, Gaye-Diallo A. Chryseobacterium indologenes in a woman with acute leukemia in Senegal: a case report. J Med Case Rep. 2014;8:138.

9. Bellais S, Naas T, Nordmann P. Genetic and Biochemical Characterization of CGB-1, an Ambler Class B Carbapenem-Hydrolyzing Beta-Lactamase from Chryseobacterium gleum. Antimicrob Agents Chemother. 2002;46:2791-6.

10. Mandell GL, Douglas, Bennett JE. Principles and Practice of Infectious Diseases. 8th ed. New York: Elsevier; 2010. p. 3022-3.

11. Hsueh PR, Teng LJ, Yang PC, Ho SW, Hsieh WC, Luh KT. Clinical and microbiological characteristics of Flavobacterium indologenes infections associated with indwelling devices. J Clin Microbiol. 1996;34:1908-13.

12. Kodama Y, Nishimura M, Nakashima K, Ito N, Fukano R, Okamura J. Central intravenous catheter-related bacteremia due to Chryseobacterium indologenes after cord blood transplantation. Rinsho Ketsueki. 2013;54:305-10.

13. Lin PY, Chen HL, Huang CT, Su LH, Chiu CH. Biofilm production, use of intravascular indwelling catheters and inappropriate antimicrobial therapy as predictors of fatality in Chryseobacterium meningosepticum bacteraemia. Int J Antimicrob Agents. 2010;36:436-40.
14. Lo HH, Chang SM. Identification, characterization, and biofilm formation of clinical Chryseobacterium gleum isolates. Diagn Microbiol Infect Dis. 2014; 79(3):298-302

15. Kirby JT, Sader HS, Walsh TR, Jones RN. Antimicrobial susceptibility and epidemiology of worldwide collection of Chryseobacterium spp. Report from the SENTRY Antimicrobial surveillance Program (1997-2001). J Clin Microbiol. 2004:42:445-8

16. Zeba B, De Luca F, Dubus A, Delmarcelle M, Simpore J, Nacoulma JO, Rossolini GM, Frere JM, Docquier JD. IND-6, a highly divergent IND-type metallo-beta-lactamase from Chryseobacterium indologenes strain 597 isolated in Burkina Faso. Antimicrob Agents Chemother. 2009;53:4320-6.

17. Ben Salah I, Fekih Hassen M, Ben Haj Khalifa A, Ben Sik Ali H, Tilouche N, Kheder M, Elatrous S. Chryseobacterium indologenes in ventilator-associated pneumonia: First reported case in Tunisia. Rev Pneumol Clin. 2015;71(6):374-5.

18. Garg S, Appannanavar SB, Mohan B, Taneja N. Pyonephrosis due to Chryseobacterium gleum: A first case report. Indian J Med Microbiol. 2015; 33(2):311-3.

\section{Submit your next manuscript to BioMed Central and we will help you at every step:}

- We accept pre-submission inquiries

- Our selector tool helps you to find the most relevant journal

- We provide round the clock customer support

- Convenient online submission

- Thorough peer review

- Inclusion in PubMed and all major indexing services

- Maximum visibility for your research

Submit your manuscript at www.biomedcentral.com/submit
Biomed Central 